\title{
Deficit discourses of Indigenous high school students in physical education and school sport and the benefit of a strengths based alternative
}

\begin{tabular}{c|c} 
John Williams & Lawrence Bamblett \\
University of Canberra & Australian National University \\
john.williams@canberra.edu.au & lawrence.bamblett@anu.edu.au \\
\hline
\end{tabular}

Keywords: Indigenous, deficit discourses, figurational sociology, physical education, sport

\begin{abstract}
This paper reports the positive aspects of participation in physical education (PE) and school sport by Indigenous students as part of the wider findings of a doctoral study carried out at three Australian Capital Territory (ACT) government secondary schools. Data was collected from Indigenous students using group interviews and figurational sociology was used to interpret the findings. Central to figurational sociology are long-term processes and power relationships and it is contended that deficit understandings are inextricably linked to these kinds of relationships between individuals and groups. In particular, the research drew upon the figurational concepts of established and outsider theory (Elias \& Scotson, 1994). This study found that Indigenous students were predominantly portrayed according to deficit understandings in both PE and in school sport. This research is important because it connects with a key idea of the Australian Curriculum Health and Physical Education (AC HPE) (ACARA, 2015). This key idea being a 'strengths based approach'. The paper concludes by identifying opportunities for Indigenous perspectives to be included in the AC HPE according to a strengths based perspective and also highlights related topics for future research. This paper is particularly relevant to primary and high school educators.
\end{abstract}

\section{Introduction}

The purpose of this research is to demonstrate how perspectives of Indigenous students at three government high schools in the Australian Capital Territory (ACT) can inform Physical Education (PE) curricula and school sport utilising a 'strengths based approach' (ACARA, 2015). Such an approach is used to inform the AC HPE (ACARA, 2015) and acknowledges that all students have personal resources that they can utilise in meeting the achievement standards of this curriculum. In contrast to this key idea, Aboriginal and Torres Strait Islander peoples have historically been portrayed by non-Indigenous Australians according to deficit understandings (Nakata, 2007). Indeed, a consistent framing of Aboriginal identity as deficient is established across different sites of representation (Fforde et. al., 2013). Sport and PE as two of the more significant sites of representation of Aborigines make significant contributions to the discourse of deficit. The story in sport is that Aborigines are athletic and disadvantaged. Over-representation in certain sports proves disadvantage and confirms Aboriginal identity in deficit terms. Pre-service HPE teachers not surprisingly hold images of Aborigines as athletic and disadvantaged. They consistently use deficit words such as problem, disadvantage, impoverished, unhealthy, bad, welfare, dependant, fragmented, violent and even uncivilised to describe Aborigines (Bamblett, 2016). This firmly places Aborigines as an out-group in comparison to the pre-service teachers. An out-group offering little of value. 
It is stated in the AC HPE that "the curriculum recognises that students have varying levels of access to personal and community resources depending on a variety of contextual factors that will impact on their decisions and behaviours" (ACARA, 2015). It is these personal and community resources of Indigenous students that this paper is most concerned with and how these have the capacity to benefit all Australians. Such a possible benefit relates to the purposes of the Melbourne Declaration on Educational Goals for Young Australians (MCEETYA, 2008) in making education more relevant for all Australians. The aim of this paper is to draw attention to the assets that the Indigenous student participants in this research possessed and illustrate how these can help all students experience PE and School Sport (PESS) in more meaningful ways. The research question for this study being how can the ideas of the Indigenous student participants and Indigenous knowledge generally be used to add value to contemporary PESS provision?

\section{Literature review}

During the mid-1950s a form of PE emerged termed 'PE-as-sport-techniques' with a skills based approach to games and sports being a primary focus (Kirk, 2010). According to Kirk (2010), PE teachers teach 'PE-as-sport-techniques' by repetition of practices that are abstract or modified versions of related sports. Rarely are sports taught in their entirety or holistically other than sometimes at the end of a topic or unit of work. Within this model of PE, instruction frequently does not progress beyond an introductory level with similar content repeated over and over again (Kirk, 2010). This form of PE is dated and has not adapted to global societal change (Kirk, 2010). As such, it is limited in its relevance through being restrictive and because of its Eurocentric focus, where content that is primarily British or American is almost exclusively taught (Fitzpatrick, 2009). At the individual teacher level, this kind of PE aligns well with the personal biographies of $\mathrm{PE}$ teachers and in particular their strong associations with sport (Green, 2000; McKay, Gore \& Kirk, 1990).

At the same time that 'PE-as-sport-techniques' became popular in many industrialised nations, the multi-activity curriculum also emerged, comprising individual physical activities or sports taught separately as short units of work (Drummond \& Pill, 2011). In common with 'PE-assport-techniques', the multi-activity curriculum has persisted and is the leading framework for teaching PE in most developed countries including Australia (Capel \& Blair, 2007; Drummond \& Pill, 2011; Tinning, 2005). This popularity is despite the multi-activity model being recognised almost 30 years ago as not allowing students enough time to develop content knowledge and skills before moving from one activity to another (O'Connor, 2006). Other limitations of the multi-activity approach are that students can be excluded because of ability, or gender and content is often poorly related to the full versions of the games and sports that occur outside of school (Hastie, 2003; O'Connor, 2006; Tinning, 2010).

The development and writing of any curriculum is biased, because the values of writers and others of influence tends to be what is most highly valued (Dinan-Thompson, 2009; Ennis, 2003; Penney \& Glover, 1998; Wright 1996). In other words, curriculum writers have relative power (Elias, 1978) in deciding what is, and what is not included, as well as what becomes privileged knowledge. According to Ennis (2003), in constructing PE curricula, writers choose what knowledge is most important for students to learn and this content comprises privileged and marginalised knowledge (Macdonald \& Tinning, 1995; Tinning, 2004). Privileged knowledge includes science-based content such as 'motor skills', 'biomechanics' and 'exercise physiology', as well as 'fitness', and 'team sports' with marginalised knowledge being dance and ethnic perspectives including Indigenous games and sports (Tinning, 2004). Similar to curriculum writers teachers also have relative power (Elias, 1978) through being able to have some autonomy over what they teach. It was found in the wider research that this study draws from, that explicitly teaching Indigenous content has been a stated requirement 
in PE curricula or generic educational policy documents at each of the three schools since the mid-1990s (Williams, 2016a). However, Aboriginal and Torres Strait Island games were found to be rarely or never taught in PE at each school (Williams, 2016b).

\section{Method}

Figurational sociology was used to inform the research design and as the theoretical framework to understand the findings. Fundamental to figurational sociology is the concept of the figuration which contends that all people exist in interdependent relationships and have varying degrees of power according to the nature of the different associations that they are part of (Elias, 1978). These relationships are subject to planned and unplanned processes that occur over time. Within the overarching doctorate research the figuration that was examined was the interdependent people and processes that are involved in providing PESS at the three schools. In this paper, our focus is on the Indigenous students as part of this figuration. However, it is noted that these students do not exist in isolation within the figuration but are inextricably linked by relational ties to other 'key players' within this PESS figuration such as principals, executive HPE teachers, classroom HPE teachers and Indigenous Education Officers (IEOs). The non-Indigenous 'key players' in the wider research were found to have a monopoly share of the power resource within the figuration (Williams, 2016b).

Before data collection, ethics approval was obtained from University of Canberra Human Ethics in Research Committee and the ACT Education and Training Directorate. Data was then collected using semi-structured individual and group interviews at each of the three schools with all participants giving signed consent for their involvement. Transcripts were made for each of the interviews and recurring themes were identified and coded that related to a 'strengths based approach'. To protect student anonymity and confidentiality each of the three schools is identified in the following section using the letters ' $A$,' ' $B$ ' and ' $C$ '.

\section{Results and discussion}

Many of the students liked PE. Most commonly it meant 'fun and enjoyment' and it provided opportunities for playing sports and hanging out with friends. 'Being outside' was another popular reason why the students liked PE along with being active, health and fitness, skill development, teamwork, and competition. The following responses were typical of many of the students:

... like just having a lot of fun... just playing games with your mates... mucking around... just sharpening your skills (student $2 \mathrm{C}$ ).

It's fun... a lot of outdoor sports. I kind of enjoy being outdoors instead of being stuck in a class all day... (student $5 \mathrm{C}$ ).

Yeah, it's good to get out and... stay healthy and fit and... play games with like your mates and that and... build like... characteristics about life and that... team skills... (student 5B).

In many respects, these responses about why the students liked PE reflected the official contemporary and historical discourse for PE contained in documents that were examined as part of the wider study. In school and system level curricula documents, school prospectuses, Year books and websites, PE as well as being fun had the purpose of encouraging students to be active while developing their skills and fitness (Williams, 2016a). When asked if there was 
anything that they would change in PE several students across the three sites thought that existing content in PE was often repetitive.

Yeah, I wouldn't change much but... I reckon... it would be better to have like more variety of... different like activities and that for PE. Because like... with my teacher we pretty much just do the same unit... and it gets kind of boring and that... and yeah (student 4B).

Similarly, in the context of more Indigenous content being taught in PE, student 9A commented:

It would be much more interesting... than a lot of the subjects (topics in PE) we do, which we do... since... like kindergarten.

The mention of repetitiveness of content reflects the shortcomings of the 'PE-as-sporttechniques' model raised by Kirk (2010). Some of the HPE teachers interviewed at the three schools as part of the wider study spoke about how there was 'no space' in the existing program to include Indigenous content (Williams, 2016b). The above student comments suggest that there is indeed space for this provision. In addition, those student remarks are also in contrast to responses at a national level to the Draft Shape of the Australian Curriculum: Health and Physical Education Consultation Report (ACARA, 2012) where teachers similarly said there was no room for additional content because of an already crowded curriculum. Those 'reasons' we contend are unjustified and instead represent cohesion by an established group in resisting infiltration by an outsider group (Elias \& Scotson, 1994).

According to Elias and Scotson (1994), established groups are people who share common values, beliefs, practices and behaviours characterised by longevity who tend to have a large share of power resources within figurations. Conversely, outsider groups have some shared beliefs as well differing values, beliefs, practices and behaviours and tend to possess a much smaller share of the power resource. In the PESS figuration studied, HPE teachers can be considered as an established group because they have common values such as their predisposition to sport and Western sport in particular (Williams, 2016a). In addition HPE teachers tended to teach 'PE-as-sport-techniques' (Kirk, 2010) using predominantly Western games and sports that had remained largely unchanged in the histories of each respective school (Williams, 2016a). Further, all of the HPE teachers were non-Indigenous and had attended teacher education at a local university where Indigenous content had not been included in PE teacher education (Williams, 2016b). We argue therefore that Indigenous content was considered as marginalised content by those teachers (Macdonald \& Tinning, 1995; Tinning, 2004). It was something that they had rarely been exposed to, particularly in a PESS context. The Indigenous students are considered an outsider group in the PESS figuration, on account of their Indigeneity and because they had limited power to influence the figuration. This lack of power was also a consequence of the Indigenous students' status as students, who by virtue of their position as children in a school have limited decision making power. Further, some of these students did not even know that there were games from their own culture (Williams, 2016b).

The students commented that Indigenous content was rarely included in PE. At School C, some Indigenous games and sports were taught but predominantly by an IEO who was not a teacher but instead a teacher support member of staff. The students were asked whether they thought Indigenous content should be included more often at school and within PE in particular. Most of the students across the three schools thought that there should indeed be 
more traditional Indigenous games or Indigenous culture in PE.

Yeah... I reckon it would be a good experience for... non-Indigenous kids plus as well as the Indigenous kids. Just to get back to their roots and stuff... just something different than all these other... games that we can learn (Student 1B).

Yes... I think it would be fun if we did it and it would be really good for other kids to... see different cultures (Student 6B).

Well l'd like some more traditional games in PE. It would just be fun just to... like show other teachers and... so they can show their classes... or... other people so they can... like tell their friends... so that... the sport can get out... and let everybody know... like there is a game... like there is traditional games. There are traditional games like... Indigenous. So there's only two games that I know... if we could get that out that would be pretty cool... because we could play schools against schools like we did last year (student 2C).

What these student points of view illustrate is that those students would welcome their wider community resources being a substantive part of the PE curricula at their schools. By HPE teachers and school authorities realising their suggestions, they would it is contended, facilitate a 'strengths based approach' (ACARA, 2015). It is possible for some of these students that PE would have more significance for them by having more connection with their culture (ACT DET, 2006). However, one student was indifferent to increased Indigenous content in PE although they thought that it would still be a good idea.

Well... I don't really mind actually if it's in there or not... but I reckon... it would be good... just to find out more about our games and that because that... was the first game l've played (unspecified Aboriginal game)... it was a traditional game. Yeah... it was pretty fun playing it (student 4B).

The students were asked why there should be more Indigenous content in PESS.

Cos it'll... show... more of the culture around... the school (student 3A).

So everyone can like... know... like... something different instead of just the normal games like soccer, and whatever (student 4A).

The students were invited to consider how they thought other students might respond to this 'new' content.

They might think it's... different (student 4A).

Through Indigenous content in PE perhaps appealing to the wider student population it may help them to become active and informed citizens of the future through greater appreciation of Indigenous culture (MCEETYA, 2008). Student 4A also thought that HPE teachers should teach these games with help from Indigenous people in the community. The students were asked how it would make them feel, having Indigenous content in PE?

l'd feel... more like l'd want to do it... I guess (student 2A). 
l'd feel like... 'a million dollars'. Just so free... like... I don't know... l'd just feel more connected... but that's... just me (student 5A).

I reckon it would make me feel excited and... like... I don't know... l'd just be a little 'cheeky person' cos l'd know how to play the game and others would be just learning... So that's kind of... an advantage to me so l'd just be the 'smart arse'... to them (laughs) (student 1B).

I think it would be more fun, more interesting (student 6B).

We'd have more fun in class and be proud (student 1C).

Just a... change... in games because usually they're all the same... and if it goes on with different games that... non-Indigenous people don't know... then they might have fun as well as doing all the other games' (student $5 \mathrm{C}$ ).

These responses show the potential for Indigenous content in PE, enabling PE and therefore school generally, to have greater significance (ACT DET, 2006) for some Indigenous students. Student 3A remarked that his school had entered the ACT Secondary School Sports Association Buroinjin competition, Buroinjin being a traditional Aboriginal ball/tag game (Australian Sports Commission, 2009) and that they had won. Student 3A was asked how that made him feel, that they had won.

Yeah, very... very good (student 3A).

The students who had played Indigenous games and sports as part of PESS were asked how participating in these activities had made them feel.

Yeah it was... I was pretty proud that they came up with a game like that (student 4B).

I wish I did do like more... stuff to do with our culture. Like, at my last High School they did... do like... sports... Indigenous sports and stuff (student 2A).

The students were asked why they thought that Indigenous games tended to be taught infrequently, if at all in PE at their schools:

Probably... some teachers don't want to teach it... some teachers do. Some teachers just don't have the respect of the Aboriginal person (student 1C).

Like I guess they've (HPE teachers) never... known the games... like... they've never known the games like Aboriginal people. Indigenous people have more knowledge than other peoples' games and stuff. I guess they've just kept it to themselves (student 2C).

I'm not... entirely sure. I reckon they should... have some... Indigenous games. Most of them can be fun... and... teach all the non-Indigenous people that... we play those sort of games (student 5 C).

These responses are insightful to some of the reasons why HPE teachers at the three schools 
rarely, if at all, taught Indigenous perspectives in PE. The response by student $1 \mathrm{C}$ about some teachers not wanting to teach Aboriginal and Torres Strait Islander perspectives in PE was consistent with what was reported in the wider doctoral research. Apathy and resistance to teaching these perspectives in common with what has been reported nationally (see ACARA, 2012) was evident in the HPE teacher interview transcripts at each school (Williams, 2016b). The comments by student $2 \mathrm{C}$ about HPE teachers not knowing about Aboriginal games is also consistent with what the HPE teachers said at their interviews (Williams, 2016b). The final response by Student $5 \mathrm{C}$ seems a fitting way to end this section because it highlights issues of social justice and equity (ACARA, 2015; MCEETYA, 2008) and that Indigenous games have a rightful place in The Australian curriculum health and physical education (ACARA, 2015).

\section{Synthesis}

In this paper it has been shown that Indigenous students at the three ACT government high schools believed that Aboriginal and Torres Strait Island games and sports should be included in a more substantive way in PESS. Students spoke about how much of the content taught in PE failed to acknowledge their culture and also suggested that contrary to the beliefs of their HPE teachers, there was 'space' for Indigenous mention in PE. Although direction to teach Aboriginal and Torres Strait Islander perspectives has been explicit in ACT government education system level generic documentation or school level PE curricula since the mid1990s, there was little evidence in the wider research that such content was taught (Williams, 2016b). This slippage serves to illustrate the relative power that HPE teachers hold as an established group (Elias \& Scotson, 1994) by having autonomy in deciding what they teach and do not teach. There was a sense that the Indigenous students while welcoming a shift to include their culture within PE had limited power to progress such change. This limited influence we argue is characteristic of the status of these Indigenous students as an outsider group that is representative of Aboriginal and Torres Strait Islander people more widely in society.

\section{Summary, conclusions and implications}

This research has highlighted the inequity of PESS provision at three government high schools in the ACT where Aboriginal and Torres Strait Island content is marginalised. The paper draws upon wider research that found that Indigenous students experienced PESS in racialised ways and were subject to broader stereotypical typecasting (Williams, 2016c). Deeper explanation about why HPE teachers did not teach Indigenous games and sport was reported from the overall doctoral research (see Williams, 2016b). However, this paper has a different focus that views the recently launched Australian curriculum health and physical education (ACARA, 2015) as an opportunity for Indigenous culture to be embraced as a 'strengths based approach' (ACARA, 2015). Nevertheless, for such a shift to happen the authors argue that a multi-faceted approach is required. Such an approach requires pre-service and in-service HPE teachers to reconsider the meaning of PESS and to ask themselves whether what we do in PESS is socially just. Perhaps what are difficult or controversial issues for some Australian HPE teachers have to be raised and possibly confronting discussion needs to take place. We contend that by having frank and open conversation at forums such as the ACT Australian Council for Health, Physical Education and Recreation 2016 Conference that the figuration described here can begin to change. Further, the Aboriginal and Torres Strait Islander Elected Body http://atsieb. com.au/ who give Indigenous Canberrians a voice, the United Ngunnawal Elders Council, local universities and schools also have a role to play in helping to include Indigenous content more meaningfully in PESS. 
There is also a need for further research. What has been discussed is one aspect of a 'strengths based approach' (ACARA, 2015). However, there are other ways in which Indigenous students in PESS can be viewed according to this approach. For example, research has already been carried out into how Aboriginal people continue their culture through Western sport and sports competitions or tournaments (Bamblett, 2011; Godwell, 1997; Norman, 2006). Genuine and meaningful inclusion of Indigenous perspectives in PESS has a much greater importance beyond the Australian curriculum health and physical education (ACARA, 2015). Embracing the traditional games and sports of Indigenous peoples in Australian schools is a step towards reconciliation. In summary, the ideas of the Indigenous students and wider knowledge of Australian Indigenous peoples can add value to contemporary PE programs in Australian schools. At the same time, this inclusion can address long term issues concerning the repetitive nature of present day PE provision. It is our intention that delegates will consider the ideas put forward in this paper and in the accompanying presentation to reflect upon their own practice and make changes to their own pedagogical practice as necessary. 


\section{References}

ACARA (Australian Curriculum Assessment and Reporting Authority). (2012). Draft shape of the Australian curriculum: Health and physical education consultation report. Retrieved from www. acara.edu.au/resource/HPE_Consultation_Report_-_04022.pdf

ACARA (Australian Curriculum Assessment and Reporting Authority). (2015). The Australian curriculum health and physical education. Retrieved from http://www.australiancurriculum.edu.au/ health-and-physical-education/curriculum/f-10?layout=1

ACT DET (Australian Capital Territory Department of Education and Training). (2006). A classroom practice guide: Quality teaching in ACT schools. Canberra: Publishing Services for the ACT Department of Education and Training.

AIATSIS (Australian Institute of Aboriginal and Torres Strait Islander Studies). (2012). Guidelines for ethical research in Australian Indigenous studies. Retrieved from http://aiatsis.gov.au/sites/default/ files/docs/research-and-guides/ethics/GERAIS.pdf

ASC (Australian Sports Commission). (2009). Yulunga. Retrieved from http://www.ausport.gov.au/ data/assets/pdf_file/0017/402191/SP_31864_TIG_resource_FINAL.pdf

Bamblett, L. (2011). Straight-line stories: Representations and Indigenous Australian identities in sports discourses. Australian Aboriginal Studies, 2, 5-20. Retrieved from https://search.informit.com.au/ fullText;dn=822640976007755;res=IELAPA

Bamblett, L. (2016). 'Winanguy: Thinking about Aboriginal Studies Research'. Keynote Address at the National Centre for Indigenous Studies, Higher Degree Research Retreat 2016. JG Crawford School, The Australian National University 19-21 October.

Baur, N. \& Ernst, S. (2011). Towards a process-oriented methodology: Modern social science research methods and Norbert Elias's figurational sociology. The Sociological Review, 59(s1), 117-139. doi:10.1111/j.1467-954X.2011.01981.x

Capel, S. \& Blair, R. (2007). Making physical education relevant: Increasing the impact of initial teacher training. London Review of Education, 5(1), 15-34. doi:10.1080/14748460701241444

Dinan-Thompson, M. (2009). Voices in health and physical education policy and practice in Australian states and territories. In M. Dinan-Thompson (Ed), Health and physical education: Issues for curriculum in Australia and New Zealand (pp. 38-59). South Melbourne: Oxford University Press.

Drummond, M. \& Pill, S. (2011). The role of physical education in promoting sport participation in school and beyond. In S. Georgakis \& K.M. Russell (Eds), Youth sport in Australia (pp. 165-178). Sydney: Sydney University Press.

Elias, N. \& Scotson, J. L. (1994). The established and the outsiders (Vol. 32). London, England: Sage Publications.

Elias, N. (1978). What is sociology? London: Hutchinson.

Ennis, C. D. (2003). Using curriculum to enhance student learning. In S. J. Silverman \& C. D. Ennis (Eds), Student learning in physical education (2nd ed., pp. 109-127). Champaign, IL: Human Kinetics.

Fforde, C. \& Bamblett, L. \& Lovett, R. \& Gorringe, S. \& Fogerty, B (2013). Discourse, deificit and identity: Aboriginality, the race paradigm and the language of representation in contemporary Australia. In Media International Australia, Incorporating Culture \& Policy. (149), 162-173.

Fitzpatrick, K. (2009). Indigenous perspectives in HPE curriculum: Contradictions and colonisation. In M. D. Thompson (Ed.), Health and physical education: Issues for curriculum in Australia and New Zealand (pp. 120-144). South Melbourne: Oxford University Press.

Godwell, D. (1997). Aboriginality and rugby league in Australia: An exploratory study of identity construction and professional sport (unpublished Master's thesis). University of Windsor, Ontario. 
Green, K. (2000). Exploring the everyday 'philosophies' of physical education teachers from a sociological perspective. Sport, Education and Society, 5(2), 109-129. doi:10.1080/713696029

Hastie, P. A. (2003). Teaching sport within physical education. In S. J. Silverman \& C. D. Ennis (Eds), Student learning in physical education (2nd ed., pp. 227-240). Champaign, IL: Human Kinetics.

Kirk, D. (2010). Defining physical education: Nature, purposes and future/s. Physical Education Matters $5(3), 30-31$.

Macdonald, D. \& Tinning, R. (1995). Physical education teacher education and the trend to proletarianization: A case study. Journal of Teaching in Physical Education, 15(1), 98-118.

MCEETYA (Ministerial Council on Education, Employment, Training and Youth Affairs). (2008). Melbourne declaration on educational goals for young Australians. Retrieved from http://www.curriculum.edu. au/verve/_resources/national_declaration_on_the_educational_goals_for_young_australians.pdf

McKay, J., Gore, J. M. \& Kirk, D. (1990). Beyond the limits of technocratic physical education. Quest, 42(1), 52-76. doi:10.1080/00336297.1990.10483979

Mennell, S. \& Goudsblom, J. (1998). Introduction. In S. Mennell \& J. Goudsblom (Eds), Norbert Elias on civilization, power, and knowledge: Selected writings (pp. 1-45). Chicago, IL: The University of Chicago Press.

Nakata, M. (2007). Disciplining the savages. Savaging the disciplines. Canberra: Aboriginal Studies Press.

Norman, H. (2006). A modern day Corroboree: Towards a history of the New South Wales Aboriginal rugby league knockout. Aboriginal History, 30, 169-186. Retrieved from http://press-files.anu.edu. au/downloads/press/p171301/pdf/article12.pdf

O'Connor, J. (2006). Making sense of teaching skills, games and sports. In R. Tinning, L. McCuaig \& L. Hunter (Eds), Teaching health and physical education in Australian schools (pp. 192-199). Frenchs Forest: Pearson Education.

Penney, D. \& Glover, S. (1998). Contested identities: A comparative analysis of the position and definitions of physical education in national curriculum developments in England and Wales and Australia. European Journal of Physical Education, 3(1), 5-21. doi:10.1080/1740898980030102

Tinning, R. (2004). Rethinking the preparation of HPE teachers: Ruminations on knowledge, identity, and ways of thinking. Asia-Pacific Journal of Teacher Education, 32(3), 241-253. doi:10.1080/1359866042000295406

Tinning, R. (2005). Physical education in Australia: An interpretative account. In U. Puhse \& M. Gerber (Eds), International comparison of physical education: Concepts, problems, prospects (pp. 51-65). Aachen: Meyer \& Meyer.

Tinning, R. (2010). Pedagogy and human movement: Theory, practice, research. New York, NY: Routledge.

Whimpress, B. (1999). Passport to nowhere: Aborigines in Australian cricket 1850-1939. Petersham: Walla Walla Press.

Williams, J. (2016a). Invented tradition and how physical education curricula in the Australian Capital Territory has resisted Indigenous mention. Asia-Pacific Journal of Health, Sport and Physical Education, 7(3), 219-234. doi: 10.1080/18377122.2016.1233803 Retrieved from http://www. tandfonline.com/doi/abs/10.1080/18377122.2016.1233803

Williams, J. (2016b). 'I didn't even know that there was such a thing as aboriginal games': a figurational account of how Indigenous students experience physical education. Sport, Education and Society, 1-13. doi:10.1080/13573322.2016.1210118 Retrieved from http://www.tandfonline.com/ doi/abs/10.1080/13573322.2016.1210118 
Williams, J. (2016c). A figurational analysis of how Indigenous students encounter racialization in physical education and school sport. European Physical Education Review. doi: 1356336X16667372 Retrieved from http://epe.sagepub.com/content/ early/2016/09/14/1356336X16667372

Wright, J. (1996). Mapping the discourses of physical education: Articulating a female tradition. Journal of Curriculum Studies, 28(3), 331-351. doi:10.1080/0022027980280306 